\title{
A Novel Approach for the Development of Communicative Competence in English in a Blended Learning Context
}

\author{
Pilar Rodríguez Arancón \\ Universidad Nacional de Educación a Distancia (UNED), Madrid, Spain \\ Email: pilar.rodriguez@madrid.uned.es \\ Elena Bárcena \\ Universidad Nacional de Educación a Distancia (UNED), Madrid, Spain \\ Email: mbarcena@flog.uned.es \\ Jorge Arús \\ Universidad Complutense de Madrid (UCM), Spain \\ Email: jarus@filol.ucm.es
}

\begin{abstract}
This paper presents the ongoing work carried out by the research group ATLAS from the UNED in its most recent project I-AGENT (Intelligent Adaptive Generic English Tutor). The aim is to combine face-toface classes with individual and collaborative work carried out using innovative ICALL (Intelligent Computer Assisted Language Learning) software. The limitations in the type of learning which can be achieved using a computer can be directly addressed with the presence of personal interaction in the classroom. Thus, activities do not have to follow a set structure of selecting just one answer, but can offer a limitless array of openness, given that there is a human tutor who can revise them. Peer feedback and collaborative activities are also a fundamental part of the learning process and all of these different methodologies are integrated in order to guide the student through the scaffolding structure of the course. The units follow the story of a person through different situations to which the student can easily relate, and the intercultural aspects of learning a second language are highlighted with each scenario. Each part of the computer-based work is consolidated in face-to-face sessions, and these deal directly with the communicative aspects which would be difficult to test purely electronically, such as free speaking and writing. The student is informed of the learning which will take place in each unit in the form of can-do statements taken from the Common European Framework of Reference for Languages: Learning, Teaching, Assessment (Council of Europe, 2001).
\end{abstract}

Index Terms - I-CALL, blended learning, CEFR, collaborative work

\section{INTRODUCTION}

The development of ICALL (Intelligent Computer Assisted Language Learning) systems presents many challenges (Heilman \& Eskenazi, 2006). There are several design and implementation issues related to the use of Artificial Intelligence (AI) and Natural Language Processing (NLP) technologies in instructional systems. ICALL programs must be able to be generic, that is, it must be possible to adapt new content into the original structure in order to expand the course or to change the information contained within it. Systems must be built for reuse and reapplication, without having to repeat the initial effort. Second, there are pedagogical and associated cognitive issues (Hubbard \& Levy, 2006). ICALL must be able to model the learning situation to some degree of scaffolding, so that it is possible to gain some insight into the progress achieved in the learning process and adapt the materials developed to the needs of each individual learner. The designers are not typically the instructors who use the system, but they must anticipate the changing needs of the curriculum and the students. They must also embed sophisticated technology in a computing environment which is usable by those who do not understand technology.

ATLAS (Artificial Intelligence Techniques for Linguistic Application) ${ }^{1}$ has attempted to focus on each of these dimensions in the development of the I-AGENT system (Intelligent Adaptive Generic English Tutor) (Bárcena \& Read, 2011). ATLAS is a multidisciplinary group of researchers from Linguistics, Pedagogy and Computer Science and belongs to UNED (www.uned.es). The group has been researching ICALL for many years and has worked on the development of several systems, the latest of which is I-AGENT. The most important characteristic of the group is the focus on linguistic application. AI is used to support the development of courses which have an extensive underlying

\footnotetext{
${ }^{1}$ ATLAS (http://atlas.uned.es) is a portal supported in part by a grant from the MCYT (FFI2008-06030). More information can be obtained from mbarcena@flog.uned.
} 
pedagogic and cognitive base. Many of the activities present an AI scaffolding structure: if the student does not achieve a certain percentage of correct answers, the system will take him/her to extra activities in order to reinforce some particular aspect of grammar which has been shown to be weak or problematic. I-AGENT is a blended learning or hybrid system (Read \& Bárcena, 2010) which tries to bridge some of the weaker characteristics of ICALL by supplementing the limited array of activities with the presence of a human instructor in face-to-face language classes. A teacher and other students can provide the answer to the limitations which hinder language software for the analysis of unrestricted student linguistic production. I-AGENT has been designed to take students from an A2 level of English to a $B 1^{2}$ in nine units following an identical AI structure; thus, it could easily be extended to more units or different levels of English below or above those mentioned. The interface for the student and the instructor is a very attractive and simple to use version of Moodle 2.0 with a definite intuitive nature.

\section{I-AGENT}

\section{A. Project Goals and Design Principles}

The theoretical framework in I-AGENT combines individual and collaborative constructivist principles and practices (Read \& Bárcena, 2010), using Systemic Functional Linguistics (henceforth SFL) (Halliday, 2005) and the CEFR's (Council of Europe, 2001) domain models, and it is implemented in ICALL architecture.

The CEFR is the most widely accepted reference for language pedagogy nowadays and has an increasing influence in the learning of languages in European countries. It provides the foundations for a clear definition of teaching and learning objectives and curricular strategies, and the necessary tools for proficiency assessment. Behind this document there is the widespread functional and communicative perspective of human language. It follows an action-oriented approach which takes into account environmental, cognitive, volitional and emotional resources, as well as the abilities specific to a learner as an individual and a social agent. We believe that the lack of underlying pedagogic principles for which the CEFR has been criticized (Komorowska, 2004) can be complemented with the depth of linguistic analysis present in SFL. ${ }^{3}$ In SFL, form matches function, extended contextual evidence is incorporated, and language is seen as constantly changing contexts of situation, so meanings are not fixed, but constantly negotiated. A text is the smallest analysable unit as "for a linguist, to describe language without accounting for text is sterile; to describe text without relating it to language is vacuous" (Halliday, 1985: 10). The length of the text is not important and it can be either spoken or written; the important factor is that it is a harmonious collection of meanings appropriate to its context.

The system functionality presents the integration of prototypical communicative language competence in the classroom with ICALL software, which is used to enable a student to apply and extend it. Each software activity has its counterpart in the classroom (Bárcena, Arús \& Rodríguez Arancón, 2010). The results of the computer-based work are subsequently consolidated in face-to-face sessions and vice-versa. In this process of blended learning, the student undertakes a series of learning stages either using a computer or in the classroom, as he/she progresses through the materials and shows (or not) evidence of learning. The class sessions focus on two aspects: the learning aspects that are most challenging for computational implementation; and teacher feedback depending on computer-based performance.

Our aim is to create an interactive multimedia environment that can be used to supplement normal classroom instruction. The environment will assist second language learners by providing them with opportunities for guided practice and instruction with a variety of discourse tasks while giving tutorial assistance to help them develop both general and specialised communicative competence. The environment will also help the language teacher by providing another set of supplementary learning tools and activities, a means of monitoring students' learning and performance, a resource for teaching that supports many levels and components of language skill development.

Another of the project's design principles is the control that the students have over their learning: every unit starts with some information about what they are going to learn and finishes with the aspects of interaction that they have improved. This information is presented in the form of can-dos taken from the CEFR. This aspect of control on the part of the student is also evident at the Lexicogrammar stage, as each individual student can decide whether he/she prefers a brief grammatical explanation about the following grammatical concepts they are going to work on, or a longer and more formal linguistic insight.

\section{B. A Sample Unit}

The course is divided into 9 units to take students from an A2 to a B1 level of English (CEFR). It is designed to take 125 hours of study or 4 European credits in a combination of ICALL units and face-to-face sessions.

The student starts working at home with Moodle. The first part of the course is a Warm-up using Internet resources or links to become familiar with the topic of the unit. The next step is a Listening activity in the form of audio or video. All of these multimedia materials follow the story of a person who goes to work abroad. He applies for a job, has an interview, gets the job, meets his colleagues at the office, goes for lunch, gets promoted, etc. The intention is that the students feel identified with the characters and find real-life situations which can be useful for them in the future. What follows is an Oral Comprehension activity with closed questions and automatic feedback from the software system. If

\footnotetext{
${ }^{2} \mathrm{~A} 2$ and B1 are two of the levels referenced in the CEFR. http://www.coe.int/t/dg4/linguistic/cadre_en.asp (accessed 1/10/2011).

${ }^{3}$ http://www.isfla.org/Systemics/ (accessed 1/10/2011).
} 
the student fails to achieve $70 \%$ of correct answers, the audio/video is made available again to the student. After playing it, a different set of Comprehension questions is presented to the student. If a $70 \%$ of correct answers is still not achieved, the student can access the script of the audio/video and proceed to complete a Listening Comprehension activity. A list of Vocabulary follows and the student can listen to the pronunciation and find the explanation of the meaning of the term in English by clicking on the word on the screen. At this point, there is a STOP in the system and the student has the first face-to-face class.

The classes are designed for a period of 90 minutes each. The teacher has a progress report of the interaction of each of the students with the I-AGENT system and also a class plan. This first class will be dedicated to Listening Comprehension, Speaking and Vocabulary, all of which are related to the specific unit they are working on.

The student can then continue the work on Moodle and go to the Lexicogrammar section based on SFL. The system will again automatically evaluate the answers and expect a 70\% level of correctness. It it is not achieved, the student can try again with or without a more thorough grammatical explanation. A different set of questions will be presented and if the $70 \%$ of right answers is not attained, the scaffolding mechanism of the system starts. The student will be taken back to a different section of questions addressing a more simple aspect of grammar related to that which is presenting difficulties. Each type of error is addressed with a different type of grammatical scaffolding, as I-AGENT tries to emulate what an experienced teacher would do in a similar case. The activities are designed to encourage the students to feel that they are not just practicing the grammatical aspects but solving real-life situations. The aim is to promote higher-order thinking (Meyer, 2003). Again, the student cannot go any further before the following class.

The second face-to-face session revises the Lexicogrammar aspects, Speaking and Vocabulary. As before, the teacher already knows the level of difficulty encountered in Moodle by each of the students in the group and will attempt to solve all queries in the classroom with direct explanations and activities on the topics.

The student can then move forward to the Culture section in Moodle at home. This section is designed to make the students think about the way people work and live in other parts of the world and debunk many of the preconceived ideas they might harbor about other countries. The section is written in a food for thought style and has closed activities with automatic evaluation and also open-ended questions which the system will send to the teacher to be evaluated. Again, the system will not allow the student to progress without another face-to-face session.

The third class is dedicated to Speaking and a Culture review in which the students will work on the same issues presented to them in the software unit. The work on the Moodle system continues with a collaborative project done from home. The type of project varies and can take the form of a WebQuest, a wiki or a PowerPoint presentation, depending on the unit. This work carried out in small groups is created to be presented in the last face-to face session to the rest of the class.

The last class, dedicated to the presentations of the work carried out by the different groups, also offers time for selfassessment and peer assessment. You can see a complete unit in APPENDIX A.

\section{SAMPLE UNIT}

\section{UNIT 1}

Notion: People and their professional lives

Function: Introducing people // Causing a good impression // Activity descriptions // Eliciting and providing precise information

\section{UNIT LEARNING GOALS}

In this unit you'll learn how to do the following in English better:

- Elicit and provide information from/into short, simple notes and texts relating to basic personal and professional matters (reading \& writing-A2).

- Understand phrases and expressions related to areas of most immediate priority (e.g., very basic personal and family information, employment), provided speech is clearly and slowly articulated (overall listening comprehension-A2).

- Give a simple description or presentation of people, living or working conditions, daily routines, likes/dislikes, etc. as a short series of simple phrases and sentences linked into a list (overall oral production-A2).

\section{WARMING UP ACTIVITY:}

Let's get started! Study the following web sites to warm up your linguistic, pragmatic and sociolinguistic competence regarding food (and eating) before you start the unit:

\section{Links related to descriptions of people from all over the world:}

http://www.talkeasy.co.uk/link/materials/es111.html $\rightarrow$ this site provides essential vocabulary for the description of either oneself or others. All people's complete descriptions should cover physical and personality features.

http://www.learn-english-today.com/idioms/idiom-categories/descriptions-people.htm $\rightarrow$ a site with idioms related to personality, character and description of people. These idioms are very useful to learn but they must be used with great precaution since some of them are rather colloquial and hence inappropriate for standard job seeking situations (interviews, etc.).

$\underline{\text { http://www.essortment.com/all/humancharacteri_riat.htm }} \rightarrow$ a short article about cultural perspectives on human characteristics and behaviour. 


\section{Links about the professional world in different cultures:}

http://hrcouncil.ca/hr-toolkit/right-people-job-descriptions.cfm $\rightarrow$ this site deals with job descriptions so it is very useful to describe your past/current job or any other job you are familiar with or would like to have. It can also be used to structure an effective job advertisement.

http://www.eslflow.com/jobsandtimelessonplans.html $\rightarrow$ a collection of sites with vocabulary and activities related to the professional world.

http://www.articlesbase.com/leadership-articles/decoding-the-workplace-communication-differences-between-the-sexes-1896324.html $\rightarrow$ an interesting article on communication within the two sexes: professional communication with men and women.

http://www.essaydepot.com/documents/cultural-differences-between-people-in-communication/8 $\rightarrow$ a few articles on topics related to cultural differences, such as intercultural communication in the workplace.

\section{Links about CVs:}

http://www.businessballs.com/curriculum.htm $\rightarrow$ a site with tips on how to write an effective CV

http://www.cvtips.com/resumes-and-cvs/cv-example.html $\rightarrow$ a list of CV templates for different types of jobs for different professional areas and purposes.

\section{Links about looking for a job:}

http://www.wikihow.com/Get-a-Job $\rightarrow$ steps to consider when looking for a job.

http://www.careerbuilder.com/Article/CB-147-Changing-Jobs-The-Top-5-Things-to-Consider-When-Looking-for-a-New-Job/ $\rightarrow$ a site with tips and reflections for the job seeker.

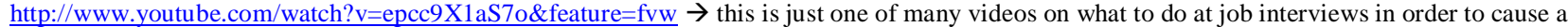
good impression and be the sucessful candidate.

http://blog.penelopetrunk.com/2009/03/06/5-things-to-do-when-youre-unemployed-hint-its-not-job-hunting/ $\rightarrow$ an alternative to job hunting - tips for the unemployed.

\section{Section: Ac-0}

Today, at home, Peter Read (a young British economist who has recently moved to Chicago) is reading the newspaper. He finds an interesting job advertisement:

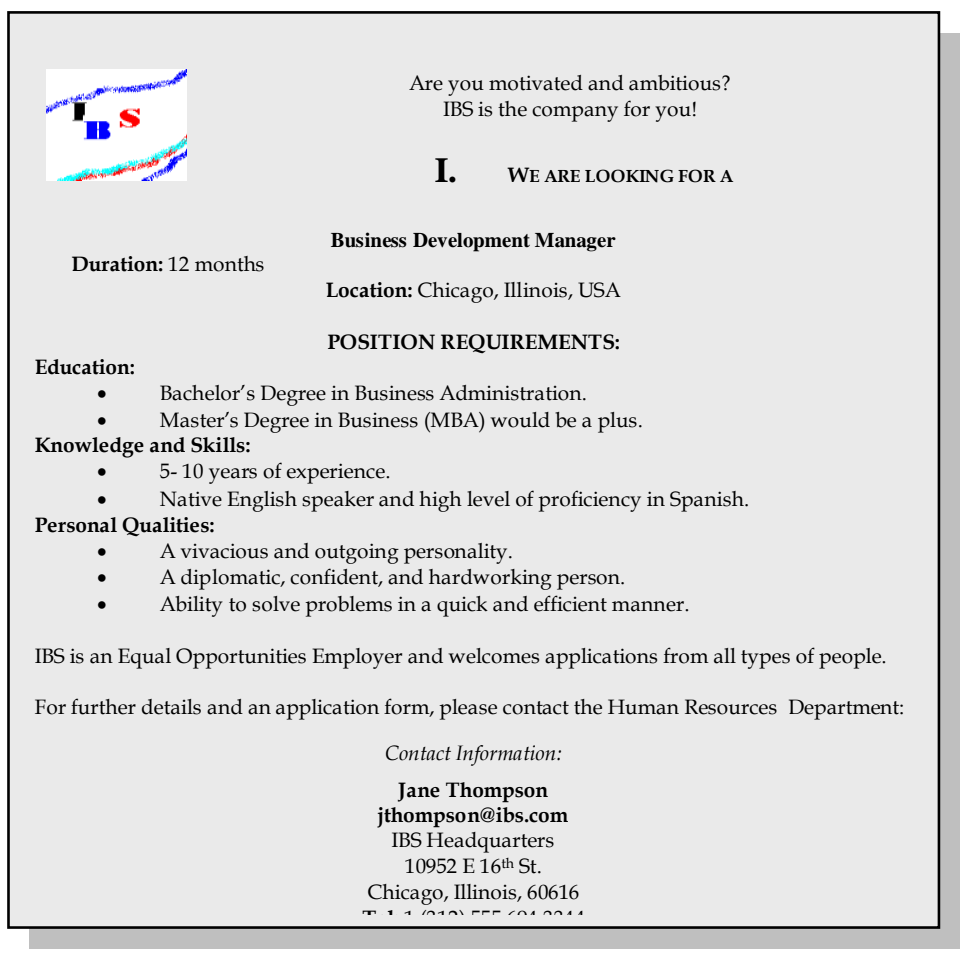

Peter thinks he is the suitable candidate so he decides to go to the company. Later on that day, he enters the secretary of the Head of Human Resources' office. Watch the video of their conversation: http://atlas.uned.es/flash/JobInterview.swf

Take a look at the personal information form that Peter has filled out: 




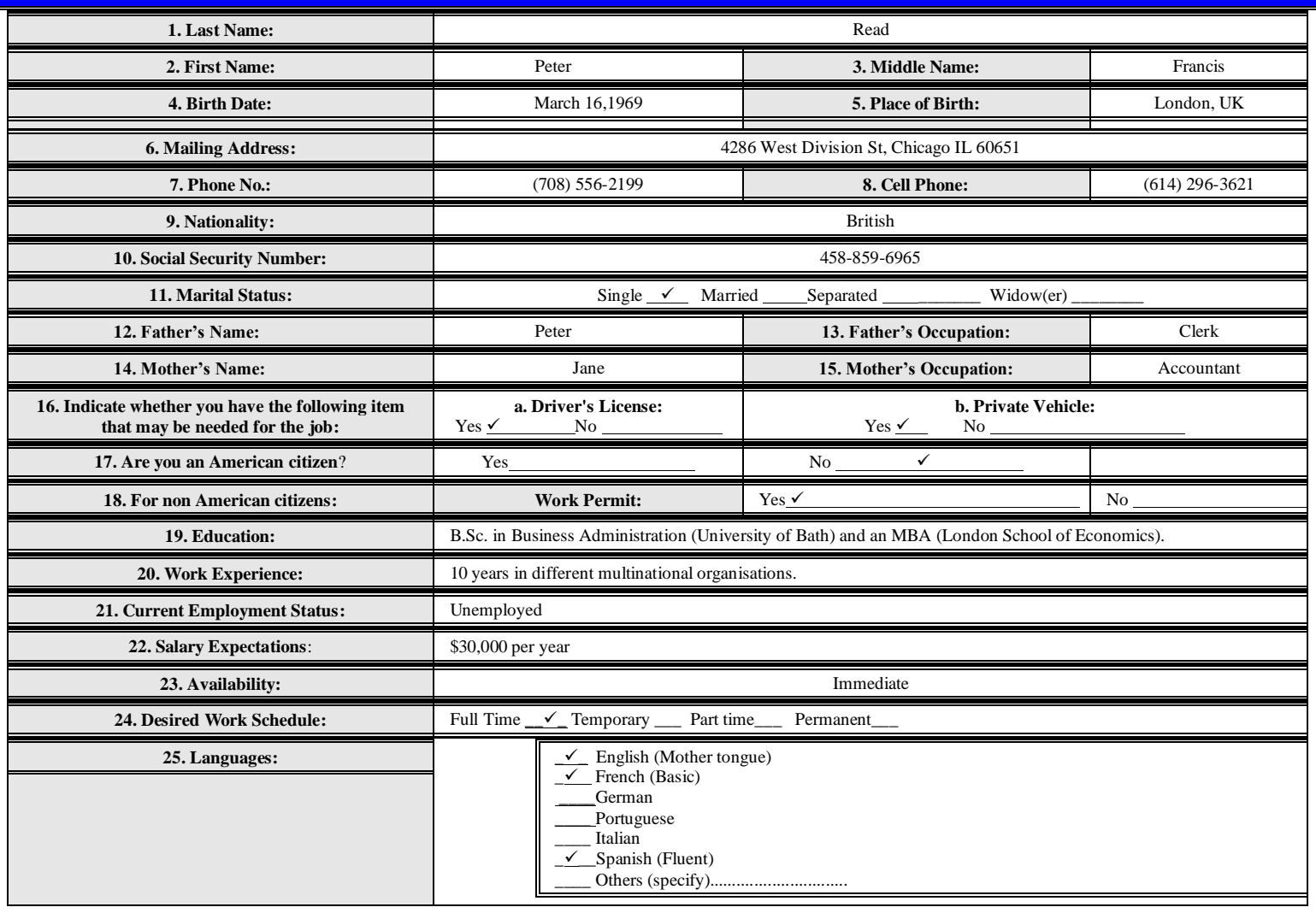

Following that visit, the secretary (Sally Cole) phones Peter for an appointment. Watch the video of their conversation: http://atlas.uned.es/flash/PhoneCall12.swf

The next day, Peter goes for an interview with the Head of Human Resources, Ms. Thompson. Watch the following two videos of the conver sations he has with her secretary:

$\underline{\text { http://atlas.uned.es/flash/SeatWaitingRoom.swf }}$

Ms. Thompson arrives a few minutes later and asks her secretary for Peter: Watch the video of their brief conversation: http://atlas.uned.es/flash/ShowHimIn.swf

Finally, Ms. Thompson interviews Peter. Watch a video of a fragment of the interview: http://atlas.uned.es/flash/FinalInterview.swf

\section{Activity for this section:}

You are talking to a friend of Peter's who wants to know about his progress looking for job. Answer the following questions based upon what you have read and seen:

1. Where has Peter found the information about the job?
A) In a letter from a friend.
B) In a newspaper advertisement
C) On the radio.

2. While at IBS, Peter wants to..
A) apply for a job
B) spell his name.
C) tell Sally his personal history.

3. Sally asks Peter to fill in a form with information about...

A) his career.
B) his personal requirements.

C) how he was brought up.

4. Who is going to interview Peter?
A) The CEO of the company.
B) Sally Cole.
C) The Head of Human Resources.

5. Peter has experience in...
A) business development
B) international business.
C) hardworking business.

ANSWERS: 1-b, 2-a, 3-a, 4-c, 5-b 
You are talking to a friend of Peter's who wants to know about his progress looking for job. Answer the following questions based upon what you have read and seen:

1. Sally Cole asks Peter to...
A) read his name.
B) write his name.
C) spell his name.

2. Sally Cole tells Peter that...
A) she will send him an email as soon as possible.
B) she will phone him.

C) she will tell him when he has to come back.

3. Peter has an interview with the Head of Human Resources at...

A) eleven o'clock.
B) half past eleven
C) ten o'clock.

4. Ms. Thompson asks Sally if...

A) Peter knows when he has to come.

B) Peter is waiting to have his interview.

C) she has called him.

5. Peter is...
A) English and a Londoner.
B) American but he lives in London.
C) English and born in Bath.

ANSWERS: 1-c, 2-c, 3-a, 4-b, 5-a

Section: Ac-2

Activity for this section:

You are talking to a friend of Peter's who wants to know about his progress looking for job. Answer the following questions based upon what you have read and seen:

1. Ms Thompson asks Peter for his...

A) job, name, nationality and hobbies.

B) nationality, job and favourite leisure activities

C) job, nationality and work experience.

2. Peter answers Ms Thompson saying that...

A) he is an expert in international business expansion

B) he is an expert at business development.

C) he is very interested in business.

3. Ms Thompson asks Peter what..

A) she can do for him.

B) he is interested in.
C) he can do for the company.

4. Peters tells Ms Thompson that...

A) he has been working hard for 15 years in international business.

B) he has had a hard experience in international business.

C) he is a person who doesn't mind working hard.

5. Peter thinks that he ...

A) is a good candidate for the job

B) has got few possibilities to get the job.

C) has to prepare a good CV for future opportunities.

ANSWERS: 1-c, 2-a, 3-c, 4-c, 5-a

Section: Ac-2

Activity for this section:

Most universities follow a three-stage study system, leading to the following titles: Bachelor/Master/Doctorate. After studying three or four years at university you get a Bachelor's degree. You can continue your education for one or two more years to get a Master's degree and, if you like research, you can get a doctorate degree or Ph.D.

What do the following university degree acronyms stand for?

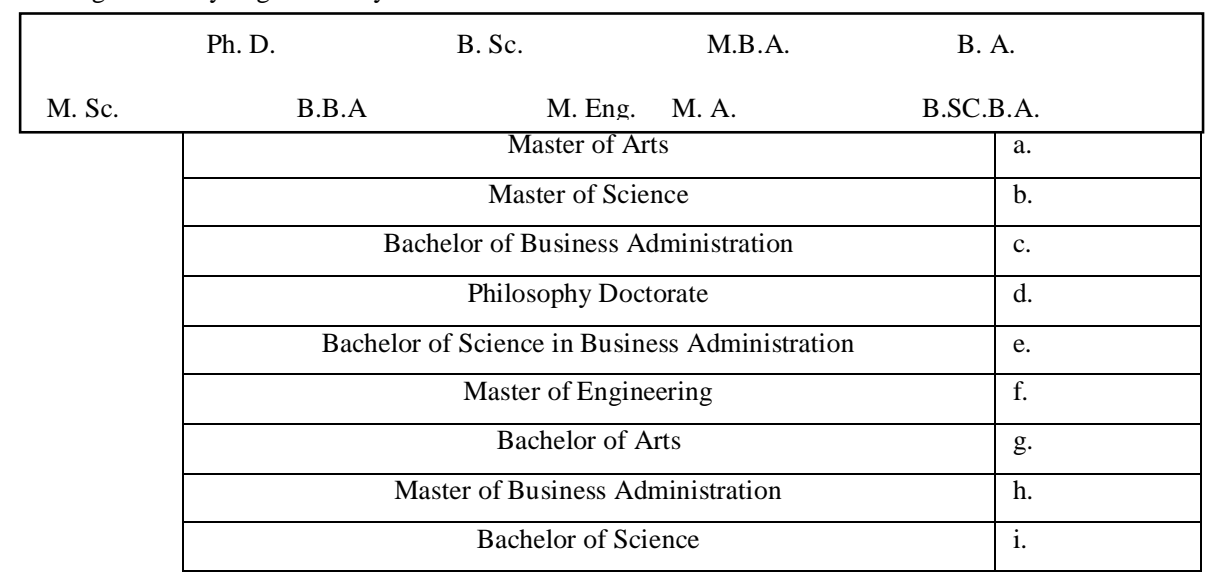

ANSWERS: a. M.A.; b. M.Sc.; c. B.B.A.; d. Ph.D.; e. B.SC.B.A.; f. M.Eng.; g. B.A.; h. M.B.A.; i. B.Sc. 
Peter Read found information on how to contact IBS in the job advertisement. IBS provided the name of the contact person, her e-mail address, the company's address, telephone number and fax. Let's see if you know how to read phone numbers, e-mail addresses, web pages, etc. in English.

Read the sentences below out loud and choose the correct answer for the underlined parts. Note that phonetic transcriptions are included between diagonal lines/(slashes):

1. IBS's telephone number is $\mathbf{5 5 5 6 9 4 3 3 4 4}$

b. /pi:// ○ $\circlearrowright /$ box one hundred and four

a. $\quad$ Five five five six nine four double three double four

b. Five hundred and fifty five, six hundred and ninety four, thirty-three, forty-four

2. Ms. Thompson's e-mail address is jthompson@ibs.com

a. /dz eı / Thompson at /aı //bı //es/ dot/Ko m/

b. Thompson at/al //bı //si:/ dot/si://o u//em/

3. Please, send all packages to P.O. Box 104

a. /pi:// o $0 /$ box one oh four

4. Chicago, Illinois, zip code is $\underline{60610}$

a. Six oh six one oh

b. Sixty thousand six hundred and ten

5. IBS's web page is www.ibs.com

a. three /'d^ bol ju:z/ dot /aı //bı //es/ dot/ si:/ /o $v / / \mathrm{em} /$

b. /'d $\wedge$ bəl ju ://'d $\mathrm{d}$ bəl ju ://'d $\wedge$ bəl ju :/ dot /aı //bı / /es/ dot /Ko m/

ANSWERS: $1 . \mathrm{a} ; 2 . \mathrm{a} ; 3 . \mathrm{a} ; 4 . \mathrm{a} ; 5 . \mathrm{b}$

\section{Section: Ac-4}

Activity for this section:

[Here if Ac-3 is answered incorrectly the student must be presented with the same test after listening to the recordings of the five sentences]

Listen to an operator from IBS giving the contact information you are being questioned on:

$$
\frac{\text { http://atlas.uned.es/Audio/IBS_Phone_Number.mp3 }}{\text { http://atlas.uned.es/Audio/MsThompsonEmail.mp3 }}
$$

http://atlas.uned.es/Audio/IBS_Web_Address.mp3

Now answer the questions again:

1. IBS's telephone number is $\mathbf{5 5 5 6 9 4 3 3 4 4}$

a. Five five five six nine four double three double four

b. Five hundred and fifty five, six hundred and ninety four, thirty-three, forty-four

2. Ms. Thompson's e-mail address is jthompson@ibs.com

a. /dz eı / Thompson at /aı / /bı / / es/ dot/ко m/

b. Thompson at / al //bı //si:/ dot/si://o v//em/

3. Please, send all packages to P.O. Box 104

a. /pi:// o $v /$ box one oh four

b. /pi:// o $v /$ box one hundred and four

4. Chicago, Illinois, zip code is $\underline{60610}$

a. Six oh six one oh

b. Sixty thousand six hundred and ten

5. IBS's web page is www.ibs.com



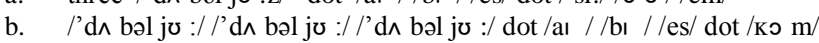

ANSWERS: $1 . \mathrm{a} ; 2 . \mathrm{a} ; 3 . \mathrm{a} ; 4 . \mathrm{a} ; 5 . \mathrm{b}$

Section: Ac-5

Activity for this section:

Peter Read was so nervous when he received IBS's phone call about the job interview that he forgot to write down the time. Now he is going to telephone IBS to check the time for his job interview the following day. Complete the telephone conversation filling in the gaps with the correct option. Remember to use formal language. 


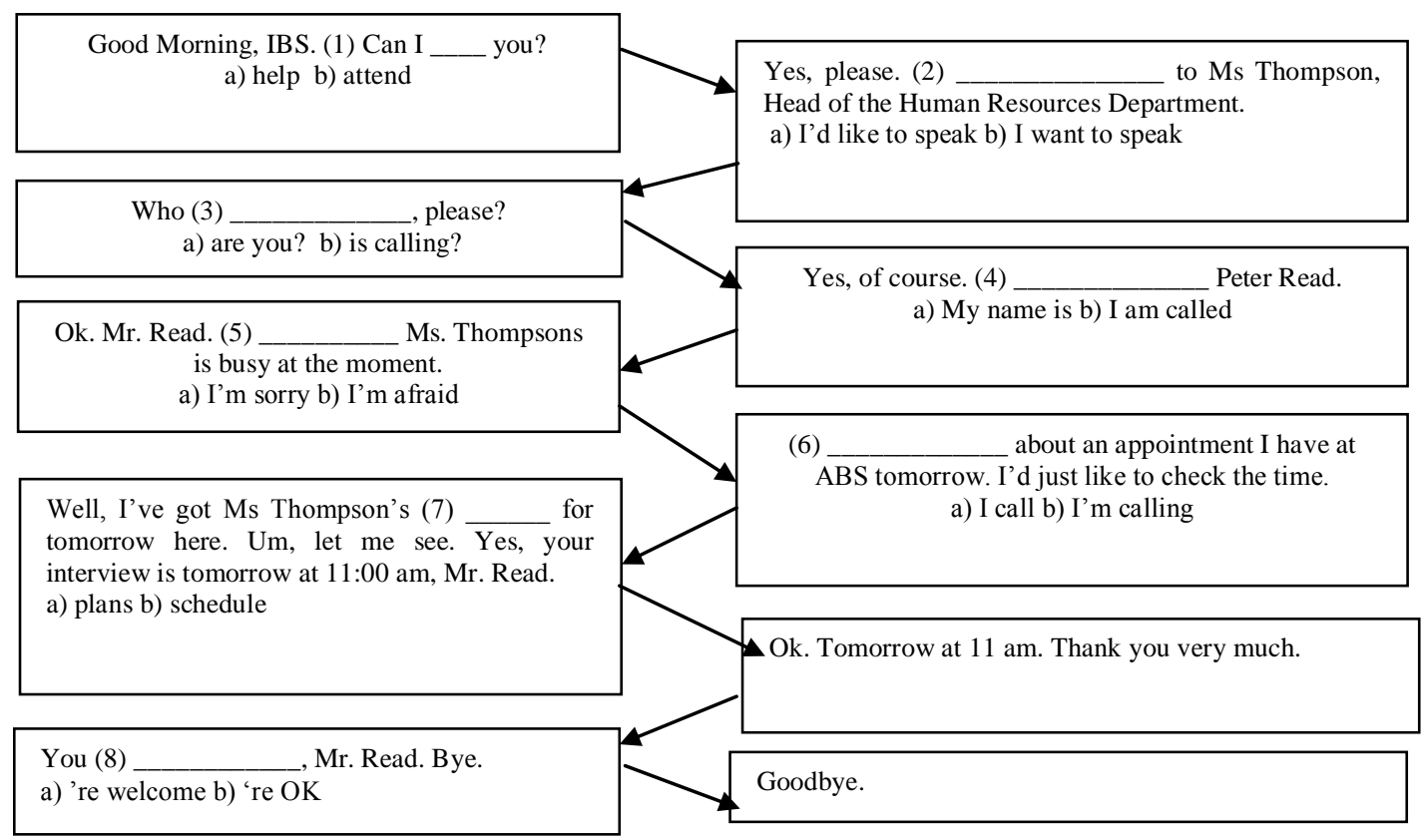

ANSWERS: 1. a; 2. a; 3. b; 4. a; 5. b; 6. b; 7. b; 8. a

Section: Ac-6

Activity for this section:

Peter Read is getting to know the people he is going to work with. Will he feel comfortable with his colleagues in the office? This is not always easy, as we are all very different. Look at the list of different personalities and think if these characteristics are generally good or bad. Then write a + (positive) or a - (negative) before the adjectives to describe the character of a person in a working environment.

\begin{tabular}{|c|c|}
\hline A natural communicator & Indecisive \\
Ability to make well thought out decisions & Persuasive \\
Able to multitask & Hard-working \\
Selfish & Efficient \\
Adaptable & Loyal \\
Cool under pressure & Responsible \\
Creative & Motivated \\
Envious & Narrow-minded \\
Dedicated & Leader \\
Lazy & Negotiator \\
Diplomatic & Open minded \\
Energetic & Well-organized \\
Unpunctual & Team player \\
Flexible & Cruel \\
\hline
\end{tabular}

ANSWERS:

\begin{tabular}{|c|c|}
\hline+ & A natural communicator \\
\hline+ & $\begin{array}{c}\text { Ability to make well thought } \\
\text { out decisions }\end{array}$ \\
\hline+ & Able to multitask \\
\hline- & Selfish \\
\hline+ & Adaptable \\
\hline+ & Cool under pressure \\
\hline+ & Creative \\
\hline- & Envious \\
\hline+ & Dedicated \\
\hline
\end{tabular}

\begin{tabular}{|c|c|}
\hline- & Lazy \\
\hline+ & Diplomatic \\
\hline+ & Energetic \\
\hline- & Unpunctual \\
\hline+ & Flexible \\
\hline+ & Hard-working \\
\hline+ & Efficient \\
\hline+ & Loyal \\
\hline+ & Responsible \\
\hline
\end{tabular}

\begin{tabular}{|c|c|}
\hline+ & Motivated \\
\hline- & Narrow-minded \\
\hline+ & Leader \\
\hline+ & Negotiator \\
\hline+ & Open minded \\
\hline- & Indecisive \\
\hline+ & Persuasive \\
\hline+ & Team player \\
\hline- & Cruel \\
\hline+ & Well-organized \\
\hline
\end{tabular}

Section: Ac-7

Activity for this section:

Most universities follow a three-stage study system, leading to the following titles: Bachelor/Master/Doctorate. After studying three or four years at university you get a Bachelor's degree. You can continue your education for one or two more years to get a Master's degree and, if you like research, you can get a doctorate degree or Ph.D. Write the following acronyms in full: 


\begin{tabular}{|c|c|}
\hline M.A. & \\
\hline M.Sc. & \\
\hline B.B.A & \\
\hline Ph.D. & \\
\hline B.SC.B.A. & \\
\hline M.Eng. & \\
\hline B.A. & \\
\hline M.B.A. & \\
\hline B.Sc. & \\
\hline
\end{tabular}

\section{ANSWERS}

\begin{tabular}{|c|c|}
\hline M.A. & Master of Arts \\
\hline M.Sc. & Master of Science \\
\hline B.B.A & Bachelor of Business Administration \\
\hline Ph.D. & Philosophy Doctorate \\
\hline B.SC.B.A. & Bachelor of Science in Business Administration \\
\hline M.Eng. & Machelor of Engineering \\
\hline B.A. & Master of Business Administration \\
\hline M.B.A. & Bachelor of Science \\
\hline B.Sc. & \\
\hline
\end{tabular}

Section: Ac-8

Activity for this section:

Peter Read found information on how to contact IBS in the job advertisement. IBS provided the name of the contact person, her e-mail address, the company's address, telephone number and fax. Let's see if you know how to read phone numbers, e-mail addresses, web pages, etc. in English.

A. Telephone numbers. Write out these phone numbers and practice reading them out loud.
a. $\quad 0075-226-6697$
b. $284-36-59710$
c. $37-9-2276313$
d. $\quad 1(312) 5556943344$
e. $\quad 1(312) 5556944433$

\section{ANSWERS}

a. double oh seven five, double two six, double six nine seven OR oh oh seven five, two two six, six six nine seven OR zero zero seven five, two two six, six six nine seven

b. two eight four, three six, five nine seven one oh OR two eight four, three six, five nine seven one zero

c. three seven, nine, double two seven six three one three OR three seven, nine, two two seven six three one three

d. one, three one two, five five five, six nine four, double three double four OR one, three one two, five five five, six nine four, three three four four

e. one, three one two, five five five, six nine four, four four three three OR one, three one two, five five five, six nine four, double four double three

B. How do you read e-mail and web pages addresses?

1. My personal e-mail is peter.read@yahoo.com

a. Peter dot Read at yahoo dot com

b. Peter point Read at yahoo point com

2. The company's official web site is www.bmw.org

a. three /'d $\wedge$ bəl ju :z/ dot /bı //em//'d $\wedge$ bəl ju :/ dot /o : ${ }^{\mathrm{r}} \mathrm{g} /$



3. Maria’s e-mail address is maria.smith@hotmail.com

a. Maria dot Smith at hotmail dot com

b. Maria dot Smith hotmail dot com

ANSWERS: 1 . a; 2. b; 3. a

Section: Ac-9

Activity for this section: 
Peter Read was so nervous when he received IBS's phone call about the job interview that he forgot to write down the time. Now he is going to telephones IBS to check the time for his job interview next day. Complete the telephone conversation filling the gaps with words or expressions from the box.

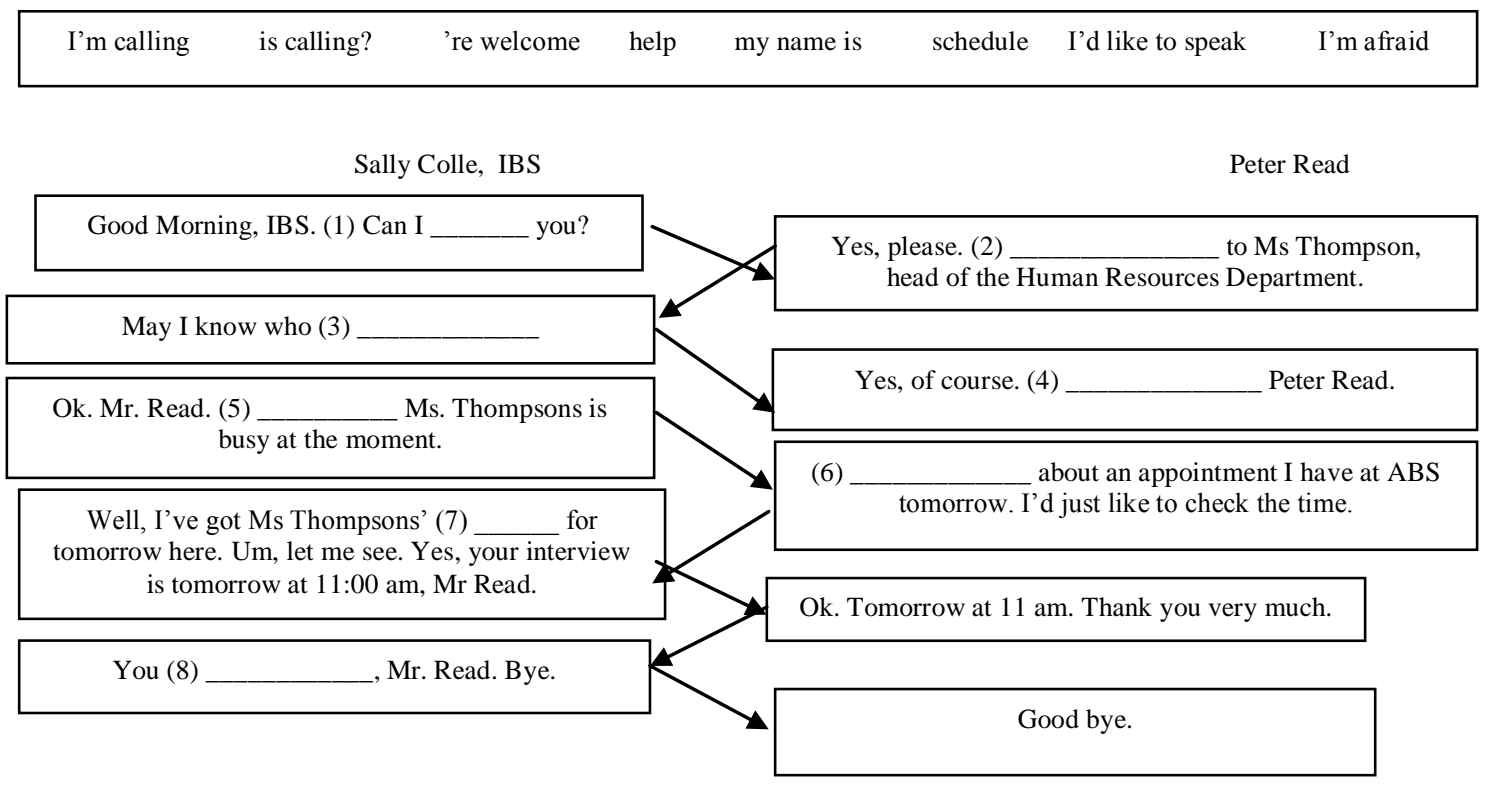

ANSWERS: 1. help; 2. I'd like to speak to; 3. is calling?; 4. my name is; 5. I'm afraid; 6. I'm calling; 7. Schedule; 9. 're welcome

\section{Section: Ac-10}

Activity for this section:

Peter Read is getting to know the people he is going to work with. Will he feel comfortable with his colleagues in the office? This is not always easy, as we are all very different. Look at the following adjectives used to describe personality traits and write them next to their definition in the sentences below.

Find the words from the box which correspond to the following descriptions:

\begin{tabular}{|ccccc|}
\hline $\begin{array}{c}\text { confident } \\
\text { dynamic }\end{array}$ & $\begin{array}{c}\text { energetic } \\
\text { selfish }\end{array}$ & $\begin{array}{c}\text { able to multitask } \\
\text { envious }\end{array}$ & $\begin{array}{c}\text { efficient } \\
\text { creative }\end{array}$ & $\begin{array}{c}\text { diplomatic } \\
\text { analytical }\end{array}$ \\
\hline
\end{tabular}

1. A logical, rational person:

2. A worker characterized by his /her continuous activity and progress:

3. Imaginative person who has originality and expressiveness:

4. Someone who is very self-assured:

5. He/she can do several things at the same time:

6. A person who has a lot of energy and enthusiasm:

7. Someone who cares only about himself/herself rather than about other people:

8. A worker who can do something well without wasting time, energy or money:

9. Someone who wants something that someone else has:

10. A person who knows how to deal with people in difficult situations:

ANSWERS: 1. analytical; 2. dynamic; 3. creative; 4. confident; 5. able to multitask; 6. energetic; 7. selfish; 8. efficient; 9. enviou s; 10. diplomatic

\section{Section: Ac-11}

a) to exchange information

b) to negotiate goods and services

When dealing with information, we can either ask for or give that information. If we ask for information, we typically ask a question, e.g. are you hungry?; if we give the information, this is typically realized by a statement: I'm hungry.

When negotiating goods and services, the choice is the same as above, that is to say, we can either ask for or give them. If we ask for some goods or for a service, the most direct way to do it is by means of a command such as pass me the salt or take me to the airport. This directness, however, can sound rude in most contexts, which is why we tend to soften our request by using a question: can you pass me the salt? or could you take me to the airport? When offering to give goods and services, we can again do it quite directly: Please take a seat or help yourself to more chicken. Being direct is less rude here than in the case of requests, as we are now making an offer. Yet, because we want to make sure we convey a polite image, we often use questions, such as: would you like more chicken?, or other constructions such as I'll drive, etc. 
Available via link (Do you want a longer grammatical explication?)

As we have seen, the combination of the notions of information and goods and services with those of giving and demanding results in four basic functions of speech: asking questions, stating, requesting and offering. In this lesson we focus on the third of these four functions, i.e. requesting. END OF EXTRA THEORY

When requesting someone to give us something or to do something for us we can use the following forms:

a) A question, typically of the can you... or could you type, as seen above. Remember that could you...? is more polite than can you...? so use can you...? when making trivial requests, especially when your interlocutor is someone you know. Using the more polite form could on those occasions could sound pedantic. Therefore, we make requests such as: can you pass me the salt? or can you unlock the door? and could I borrow a euro? or could you tell me how to get to...? (to a stranger in the street).

b) There are other more polite questions to make requests, which we use when we think that our request could meet some resistance, e.g. do you think I could borrow your car this evening? I was wondering if you wouldn't mind helping me with my homework (this is an indirect question). Remember that the longer your request form is, the more polite it will normally sound.

c) A command, typically used when the request is very trivial and we know the other person well. The force of the command is softened by accompanying it with please or will you?: sign here; please, close the door, will you?

It is important to know not only how to make a request but also how to respond to one. When giving an a ffirmative response, typical realizations are: sure, certainly (in response to more formal requests), of course (if you want to stress your will to satisfy the request) or (only for services, not for goods) no problem. When we feel we can't comply with the request, we need to make sure our refusal does not create an embarrassing situation. We need therefore to use a more polite expression than for affirmative answers, such as: I'm afraid I can't (ideally followed by a reason): because...

\section{Activity for this section:}

Now let's complete the following fragments of conversation that are typically heard in working environments. Please use the same structure as in the examples provided:

Note that the activities have been ordered in increasing degree of politeness.

1. Ex. Sign/here: Sign here, please.

a) ...Follow/me.

b) ...Fill in/form.

c) $\quad \ldots$ Meet $/ \mathrm{me} /$ noon.

d) $\quad .$. Take/seat.

2. Ex. Sign/here: Sign here, will you.

a) $\quad . . . F a x / l e t t e r$.

b) $\quad$..Fill in/form.

c) $\quad$...Meet $/ \mathrm{me} / \mathrm{noon}$.

d) $\quad \ldots$ Pass $/ \mathrm{me} /$ folder.

3. Ex. Sign/here: Can you sign here?

a) $\quad . .$. Fax/letter.

b) $\quad \ldots$. Fill in/form.

c) $\quad$...Meet $/ \mathrm{me} / \mathrm{noon}$.

d) $\quad .$. Pass $/ \mathrm{me} /$ folder.

4. Ex. Put/me/through to Human Resources: Could you put me through to Human Resources?

\section{ANSWERS}

1.

a. Follow me, please

b. Fill in this/the form, please.

c. Meet me at noon, please.

d. Take a seat, please.

a) $\quad$...Fax/letter/for me.

b) ...Fill in/form.

c) ...Meet $/ \mathrm{me} /$ noon

d) $\quad .$. Ask/her to come to my office.

5. Ex. I/borrow/your laptop: Do you think I could borrow your laptop?

a) $\quad$...I/use/your phone.

b) $\quad \ldots$ you/meet my client.

c) ...I/take/the day off.

d) $\quad$...you/change/shifts/with me?

6. Ex. I/borrow/your laptop: I was wondering if I could borrow your laptop.

a) ...I/use/your phone.

b) $\ldots$ you/meet my client.

c) $\ldots . \mathrm{I} /$ take/the day off.

d) ...you/change/shifts/with me?

2

a. Fax this letter, will you?

b. Fill in this/the form, will you?

c. Meet me at noon, will you?

d. Pass me that folder, will you?

3

a. Can you fax this letter?

b. Can you fill in this form?

c. Can you meet me at noon?

d. Can you pass me the folder?

5

a. Could you fax this letter for me?

b. Could you fill in this form?

c. Could you meet me at noon?

d. Could you ask her to come to my office?

a. Do you think I could use your phone?

b. Do you think you could meet my client?

c. Do you think I could take the day off?

d. Do you think you could change shifts with me?

a) to exchange information

b) to negotiate goods and services

When dealing with information, we can either ask for or give that information. If we ask for information, we typically ask a question, e.g. are you hungry?; if we give the information, this is typically realized by a statement: I'm hungry.

a. I was wondering if I could use your phone.

b. I was wondering if you could meet my client.

c. I was wondering if I could take the day off.

d. I was wondering if you could change shifts with me.

When we speak, we mostly do it for either of two basic purposes: 
When negotiating goods and services, the choice is the same as above, that is to say, we can either ask for or give them. If we ask for some goods or for a service, the most direct way to do it is by means of a command such as pass me the salt or take me to the airport. This directness, however, can sound rude in most contexts, which is why we tend to soften our request by using a question: can you pass me the salt? or could you take me to the airport? When offering to give goods and services, we can again do it quite directly: Please take a seat or help yourself to more chicken. Being direct is less rude here than in the case of requests, as we are now making an offer. Yet, because we want to make sure we convey a polite image, we often use questions, such as: would you like more chicken?, or other constructions such as I'll drive, etc.

\section{$\underline{\text { Available via link (Do you want a longer grammatical explication?) }}$}

As we have seen, the combination of the notions of information and goods and services with those of giving and demanding results in four basic functions of speech: asking questions, stating, requesting and offering. In this lesson we focus on the third of these four functions, i.e. requesting. END OF EXTRA THEORY

When requesting someone to give us something or to do something for us we can use the following forms:

a) A question, typically of the can you... or could you type, as seen above. Remember that could you...? is more polite than can you...? so use can you...? when making trivial requests, especially when your interlocutor is someone you know. Using the more polite form could on those occasions could sound pedantic. Therefore, we make requests such as: can you pass me the salt? or can you unlock the door? and could I borrow a euro? or could you tell me how to get to...? (to a stranger in the street).

b) There are other more polite questions to make requests, which we use when we think that our request could meet some resistance, e.g. do you think I could borrow your car this evening? I was wondering if you wouldn't mind helping me with my homework (this is an indirect question). Remember that the longer your request form is, the more polite it will normally sound.

c) A command, typically used when the request is very trivial and we know the other person well. The force of the command is softened by accompanying it with please or will you?: sign here; please, close the door, will you?

It is important to know not only how to make a request but also how to respond to one. When giving an affirmative response, typical realizations are: sure, certainly (in response to more formal requests), of course (if you want to stress your will to satisfy the request) or (only for services, not for goods) no problem. When we feel we can't comply with the request, we need to make sure our refusal does not create an embarrassing situation. We need therefore to use a more polite expression than for affirmative answers, such as: I'm afraid I can't (ideally followed by a reason): because...

Remember to follow the structure given in the examples:

1. Ex. Sign/here: Sign here, please.

a) ...File/documents.

b) $\quad .$. Book $/$ meeting room.

c) $\quad \ldots$ Call/in/applicant

d) $\quad .$. Find $/ \mathrm{me} / \mathrm{Mr}$. Brown's phone number.

2. Ex. Sign/here: Sign here, will you.

a) ...Fax/letter.

b) $\quad$...File/documents.

c) ...Book $/$ meeting room.

d) $\quad$...Pass $/ \mathrm{me} /$ folder.

3. Ex. Sign/here: Can you sign here?

a) ...Fax/letter.

b) ...File/documents.

c) $\quad$...Book $/$ meeting room

d) $\quad .$. Pass $/ \mathrm{me} /$ folder.

4. Ex. Put/ me/ through to Human Resources: Could you put me through to Human Resources?

\section{ANSWERS:}

1 .

a. File the documents, please

b. Book the meeting room, please

c. Call in the applicant, please

d. Find me Mr. Brown's number, please

a) $\quad$...File/documents.

b) $\quad \ldots$ Sign $/$ here.

c) $\quad$...Find $/ \mathrm{me} / \mathrm{Mr}$. Brown's phone number.

d) $\quad .$. Ask/her to come to my office.

5. Ex. I/borrow/your laptop: Do you think I could borrow your laptop

a) $\quad$. You/come to the office/on Saturday morning.

b) $\quad . . \mathrm{I} / \mathrm{use} /$ your computer.

c) $\quad \ldots \mathrm{I} / \mathrm{schedule}$ an appointment $/$ see her.

d) $\ldots$...you/show $/ \mathrm{me} /$ where the accounting department is?

6. Ex. I/borrow/your laptop: I was wondering if I could borrow your laptop

a) $\quad .$. You/come to the office/on Saturday morning.

b) $\quad . . \mathrm{I} / \mathrm{use} /$ your computer.

c) $\quad . . \mathrm{I} / \mathrm{schedule}$ an appointment/see her.

d) $\quad .$. you $/$ show $/ \mathrm{me} /$ where the accounting department is?

2

a. Fax this letter, will you?

b. File these documents, will you?

c. Book the meeting room, will you?

d. Pass me that folder, will you?

3

a. Can you fax this letter?

b. Can you file these documents?

c. Can you book the meeting room?

d. Can you pass me the folder?

4

a. Could you file these documents? b. Could you sign here?

c. Could you find me Mr. Brown's phone number?

d. Could you ask her to come to my office?

5

a. Do you think you could come to the office on Saturday morning?

b. Do you think I could use your computer?

c. Do you think I could schedule an appointment to see her?

d. Do you think you could show me where the accounting department is?

6

a. I was wondering if you could come to the office on Saturday morning.

b. I was wondering if I could use your computer.

c. I was wondering if I could schedule an appointment to see her.

d. I was wondering if you could show me where the accounting department is. 
Respond to the following requests as in the examples. If b. contains simply "yes", reply with sure or certainly, depending on the request's degree of formality; if it says "emphatic yes", then answer with of course; if "only for services", then no problem, if it contains "No", then I'm afraid I can't, plus the cause specified.

Ex. $1 \quad$ a. File the documents, please

b. Yes

Answer: Sure

Ex. 2 a. Do you think I could use your computer?

b. Yes

Answer: Certainly

Ex. 3 a. Book the meeting room, will you?

b. No. Booking application not working

Answer: I'm afraid I can't. The booking application is not working

1. a. Call in the applicant, please

b. Yes

2. a. Do you think I could take the day off?

b. Only for services

3. a. Do you think you could attend the meeting in my place?

b. No. Meeting a client

4. a. Do you think I could schedule an appointment to see her?

b. Only for services

5. a. I was wondering if you could show me where the computer department is

b. Emphatic yes

6. a. Call me when you get to the office, please

b. No. Not going to the office

7. a. I was wondering if I could use your phone

b. Yes

8. a. Meet me at noon, please

b. Yes

9. a. Do you think you could come to the office on Saturday morning?

b. No. Taking son to school event

10. a. I was wondering if you could stay in the office a little longer today

b Emphatic yes

ANSWERS: 1 . Sure: 2. No problem; 3. I'm afraid I can't. I'm meeting a client/I have to meet a client; 4. No problem; 5. Of course; 6. I'm afraid I can't. I'm not going to the office; 7. Certainly; 8. Sure; 9. I'm afraid I can't. I'm taking my son to a school event/I have to take my son to a school event; 10. Of course.

\section{Section: Ac-14}

Look at the structure in the following sentences:

I would really appreciate it if you could send me information about the various options available for investment in IBS or in IBS related firms.

If you preferred to invest in mutual funds or bonds, it would be simpler in terms of minimum deposit amounts. Now choose the correct option from the ones given:

1. If I lost my job, I... many problems in getting another one.

$$
\begin{aligned}
& \text { a. would have } \\
& \text { b. will have } \\
& \text { c. have }
\end{aligned}
$$

d. has

2. If I were you..

a. you'd resign rather than wait to be sacked.

b. I'd resign rather than wait to be sacked.

c. I'd have a lot of problems related to you.

d. we could talk it over.
3. You would be more aware of people's ideas if you ... less.

a. speak

b. would speak

c. spoke

d. will speak

4. If you ... the job, you would regret it later.

a. not take

b. took not

c. wouldn't take

d. didn't take

ANSWERS: $1 . \mathrm{a} ; 2 . \mathrm{b} ; 3 . \mathrm{c} ; 4 . \mathrm{d}$

\section{Section: Ac-15}

To express obligation and prohibition in English we also use a series of special verbs, called MODAL VERBS. There are various modal verbs. We use modal verbs before other verbs and in tags and short answers. Modal verbs are not followed by infinitives or participles.

The modal verb used for orders or strong suggestions, advice and opinions is MUST; for example:

You must stop smoking.

You must work hard if you want to get a promotion.

However, if we are giving a less strong suggestion, advice or opinion, we use SHOULD/ SHOULDN'T; for example:

You should be careful with wet floor.

People should arrive on time.

You shouldn't disturb them.

OUGHT TO is similar to SHOULD, but it is a modal followed by TO: 
This shop ought to accept credit cards.

People ought to be silent.

Another verb that expresses obligation is HAVE (GOT) TO. It is not a modal verb, but it acts as an auxiliary verb (that is, it never takes do/does/did). HAVE (GOT) TO is very similar to MUST to express obligation, but the main difference is that MUST usually expresses the feelings and wishes of the speaker/hearer, and HAVE (GOT) TO often expresses obligations that come from somewhere else.

Must you wear that old shirt? (Is that what you want?)

Do you have to wear a tie at work? (Is there a rule?)

POST-IT: We often use SHOULD in questions when we are wondering what to do:

Should I change my job or stay where I am?

We use MUST NOT/ MUSTN'T in prohibitions or negative orders:

You mustn't park in this area.

People must not enter these premises.

We use DO NOT HAVE TO/ DON'T HAVE TO, DO NOT NEED TO/ DON'T NEED TO or NEED NOT to say that something is unnecessary:

Peter doesn't have to work today.

You don't need to pay now. Tomorrow is just fine.

\section{Activity of this section}

Which do you think is better in the following contexts: MUST or SHOULD?

1. Visitors are reminded that they_____ show a valid passport when boarding.

2. I really go on a diet. I'll start today!

3. He thinks men ____ wear jackets and ties at all times.

4. All employees____ report to the Human Resources Manager by midday.

5. You know, I think you _____ take a holiday.

6. You absolutely ___ check the tyres before you take the car out today.

ANSWERS: 1. must; 2. should; 3. should; 4. must; 5. should; 6. must

\section{Section: Ac-16}

Culture

Job hunting or job seeking is the act of looking for employment, due to unemployment or being unhappy with a current position. The immediate goal of job seeking is usually to be invited to a job interview with an employer, which may lead to getting hired. The job hunter or seeker typically first looks for job vacancies or employment opportunities. The most common methods of job hunting are:

- looking through the classified advertisements in newspapers.

- using a private or public employment agency or recruitment agency

- looking on a company's web site for job opportunities, typically via its applicant tracking system

- finding a job through a friend or an extended business or personal network

Contacting as many people as possible is a highly effective way to find a job. It is estimated that $60 \%$ or more of all jobs are found through networking. Job recruiters may use online social networking sites for this purpose.

One can also go and hand out résumés or Curriculum Vitae to prospective employers. Another recommended method of job hunting is cold calling or emailing companies that one desires to work for and enquire whether there are any job vacancies.

After finding a desirable job, the next step is to apply for it by replying to the advertisement. This may mean applying through a website, emailing or mailing a hard copy of your résumé to a prospective employer. Once an employer has received your résumé together with those from other candidates, they will make a list of potential employees to be interviewed based on the information provided. Some basic information about an employer should be researched before applying for the job, including their full name, location, web site, business description, etc.

Curriculum vitae is loosely translated as [the] course of [my] life. The purpose of a CV is to inform prospective employers of a job seeker's qualifications and experience for a position. Writing a CV is a slow process. It is important to keep in mind the companies that you are sending it too. It is very common for employers in English speaking countries to expect to find information about voluntary work carried out or hobbies and activities which interest you. It is a way to discover more about the sort of person, character and personality of the prospective employee.

Read the following texts and answer the questions:

1. In XXXXX a CV is short (usually a maximum of 2 sides of A4 paper), and therefore contains only a summary of the job seeker's employment history, qualifications and some personal information. It is often updated to change the emphasis of the information according to the particular position the job seeker is applying for. Many CVs contain keywords that potential employers might pick up on and displays the content in the most flattering manner brushing over information like poor grades.

Which area/country does this text refer to?
A) The United Kingdom.
B) Germany.
C) The European Union.

2. In XXXXX, a CV is used specifically in academic circles and medical careers and is far more comprehensive; the term résumé is used for most recruitment campaigns. A CV elaborates on education to a greater degree than a résumé and is expected to include a comprehensive listing of professional history including every term of employment, academic credential, publication, contribution or significant achievement. In certain professions, it may even include samples of the person's work and may run to many pages.

Which area/country does this text refer to?
A) Australia.
B) The United States and Canada.
C) Portugal. 
3. In XXXXX, there has been an attempt to develop a standardized CV model and promoted to ease skilled migration between countries, although this is not widely used in most contexts. It is meant to be just as helpful to employers and education providers as it is to students and job seekers. It was designed to help them understand what people changing between the countries have to offer, whilst overcoming linguistic barriers.

Which area/country does this text refer to?
A) Peru.
B) South Africa.
C) The European Union.

4. Companies in XXXXX prefer not to receive a CV at all in application, but rather produce their own application form which must be completed in applying for any position. Some also allow applicants to attach a CV in support of the application. The reason some companies prefer to process applications this way is to standardize the information they receive, as there can be many variables within a $\mathrm{CV}$ and, therefore, the company often does not get all the information they require at application stage.

Which area/country does this text refer to?
A) The United Kingdom.
B) Many places.
C) Russia.

5. In XXXXX, résumés always include a picture of the applicant, and other information, such as religion, resident registration number, family information, military information (for men), and other information often regarded as personal information in the West.

Which area/country does this text refer to?

$\begin{array}{lll}\text { A) Korea. } & \text { B) Japan. } & \text { C) Russia. }\end{array}$

ANSWERS: 1 - A, 2 - B, 3 - C, 4 - B, 5 - A.

\section{Section: Ac-17}

1. Complete the following texts with the appropriate words:

A. In the United ___ (1) and Canada, a CV is used specifically in academic circles and medical careers and is far more comprehensive; the term $\quad$ (2) is used for most recruitment campaigns. A $\quad$ (3) elaborates on education to a greater degree than a résumé and is expected to credential, publication, contribution or significant achievement. In certain___ (5), it may even include samples of the person's work and may run to many pages.

Answers: 1. States; 2. Résumé; 3. CV; 4. Employment; 5. Professions.

B. Companies in many countries prefer not to receive a CV at all in application, but rather produce their own application (1) which must be completed in applying for any ____ (2). Some also allow applicants to attach a CV in support of the application. The reason some (3) prefer to process applications this way is to standardize the variables within a $\mathrm{CV}$ and, therefore, the company often does not get all the information they Answers: 1 . form; 2 . position; 3 . companies; 4 . information; 5 . require.

(4) they receive, as there can be many (5) at application stage.

C. In Korea, résumés always include a (1) of the applicant, and other information, such as religion, (2) registration number, family (3), military information (for men), and (4) information often regarded as (5) information in the West. Answers: 1. photograph; 2. resident; 3. information; 4. other; 5. personal.

D. In the United Kingdom a CV is short (usually a maximum of 2 sides of

(1) paper), and therefore contains only a (2) of the job seeker's employment____ (3), qualifications and some personal information. It is often ____ (4) to change the emphasis of the information according to the particular position the job seeker is applying for. Many CVs contain keywords that potential employers might pick up on and displays the content in the most flattering manner brushing over information like poor (5). Answers: 1. A4; 2. summary; 3. history; 4. updated; 5. grades.

E. In the European Union, there has been an attempt to develop a standardized CV model and promoted to ease skilled (1) between (2), although this is not widely used in most contexts. It is meant to be just as helpful to employers and providers as it is to students and job ___ (4). It was designed to help them understand what people changing between the countries have to offer, whilst overcoming ___ (5) barriers.

Answers: 1. migration; 2. countries; 3. education; 4. seekers; 5. linguistic.

2. After reading that section, could you describe how to write a CV in order to get a position in your own company/country? Please write it down and take it to class to share with other students.

3. Please write a cover letter to apply for a job vacancy in the United States or the UK. You can visit these web pages to guide you in this task: http://en.wikipedia.org/wiki/Cover_letter http://www.exeter.ac.uk/employability/students/cvcreator/index.php

\section{UNIT LEARNING RESULTS}

After the study of this unit you can now do the following in English better:

- Elicit and provide information from/into short, simple notes and texts relating to basic personal and professional matters (reading \& writing-A2) - Understand phrases and expressions related to areas of most immediate priority (e.g., very basic personal and family information, employment), provided speech is clearly and slowly articulated (overall listening comprehension-A2)

- Give a simple description or presentation of people, living or working conditions, daily routines, likes/dislikes, etc. as a short series of simple phrases and sentences linked into a list (overall oral production-A2) 


\section{CONCLuSIONS}

Approaches to second language instruction focusing on general language competence have traditionally emphasized the teaching of vocabulary, phonology, morphology, and syntax, but in recent years emphasis has shifted to the development of discourse communication skills in the second language (e.g., Krashen, 1982). Language learning is not seen merely as acquiring the knowledge of the rules of grammar, but also as acquiring the ability to use it to communicate (Barlow \& Kemmer, 2000; Croft, 2001; Widdowson, 1978). However, when viewed from the perspective of ICALL, there are still many problems to be addressed as there is a need to bridge the difficulty presented in the evaluation of unrestricted linguistic student production. Free or open-ended written answers by students cannot be automatically evaluated and the same applies to oral or spoken production as voice recognition software is still in its infancy (Bain, Basso \& Wald, 2002).

I-AGENT is an on-going project which blends face-to-face classes with innovative ICALL software in order to offer the possibility of evaluating all those aspects which a computer cannot. The software uses a systemic-functional approach integrated with the notional-functional syllabus model from the CEFR, and a cognitive and social constructivist pedagogic framework that enables individual and collaborative learning. After prototypical communicative language competence is acquired in the classroom, the ICALL software allows the student to apply and extend it. Each software activity has its counterpart in the classroom; thus, the computer-based work and face-to-face sessions work together to subsequently consolidate the knowledge, following the constructivist paradigm. Work in parallel is being undertaken by linguists (units that form the course and implementation in Moodle) and computer scientists (development of the Artificial Intelligence engine).

I-AGENT is about to start its final phase, being tested with a number of students at an important school of languages called International House in Madrid (www.ihes.com). Founded in 1953, International House is a network of 140 language schools around the world, all committed to the highest standards in education and business. We hope to report on the findings of this evaluation phase of the project at a later stage in the near future.

\section{REFERENCES}

[1] Bain, K., S. H. Basso \& M. Wald. (2002). Speech recognition in university classrooms: Liberated learning project. In Proceedings of the fifth international ACM conference on assistive technologies assets '02, 192-196.

[2] Bárcena, E., J. Arús \& P. Rodríguez Arancón. (2010). A new methodological proposal for professional English blended learning based on the integration of individual and collaborative activities. In J. L. Bueno, D. González Álvarez, U. K. Torrado, A. E. Martínez Insua, J. Pérez Guerra, E. Rama \& R. Rodríguez Vázquez (eds.), Analizar datos > Describir variación / Analysing data > Describing variation. Servizo de Publicacións de la Universidade de Vigo (CD-ROM), 594-602.

[3] Bárcena, E. \& T. Read. (2011). The integration of ICALL-based collaboration with the English classroom. In New trends in CALL. Macmillan ELT: Oxford.

[4] Barlow, G. M. \& S. Kemmer. (2000) (eds). Usage-based models of language. Stanford: CSLI.

[5] Council of Europe. (2001). Common European framework of reference for languages: Learning, teaching, assessment. http://www.coe.int/t/dg4/linguistic/Source/Framework_EN.pdf (accessed 16/4/2011).

[6] Croft, W. (2001). Radical construction of grammar. London: Oxford University Press.

[7] Halliday, M. A. K. (1985). An introduction to functional grammar. London: Arnold.

[8] Halliday, M. A. K. (2005). Computational and quantitative studies. London: Continuum.

[9] Heilman, M. \& M. Eskenazi. (2006). Language learning: Challenges for intelligent tutoring systems. In Proceedings of the workshop of intelligent tutoring systems for ill-defined tutoring systems. Eight international conference on intelligent tutoring systems, 20-28.

[10] Hubbard, P. \& M. J. Levy. (2006). Teacher education in CALL. Philadelphia: John Benjamins.

[11] Komorowska, H. (2004). CEF in pre- and in-service teacher education. In K. Morrow (ed.), Insights into the common European framework. Oxford: Oxford University Press, 55-64.

[12] Krashen, S. D. (1982). Principles and practice in second language acquisition. Oxford: Pergamon Press.

[13] Meyer, K. A. (2003). Face-to-face versus threaded discussions: The role of time and higher-order thinking. JALN 7.3, 55-65.

[14] Moodle. http://moodle.org/ (accessed 23/3/2011).

[15] Read, T. \& E. Bárcena. (2010). New perspectives for ICALL in blended language learning. In A. Szücs \& A. W. Tait (eds.), Media inspirations for learning. Budapest: University of Technology and Economics.

[16] Weasenforth, D. (2002). Realizing constructivist objectives through collaborative technologies: Threaded discussions. Language Learning \& Technology 6.3, 58-86.

[17] WebQuest. http://webquest.org/index.php (accessed 7/5/2011).

[18] Widdowson, H. G. (1978). Teaching language as communication. London: Oxford University Press.

[19] Wiki. http://www.wikispaces.com/ (accessed 23/4/2011).

Pilar Rodríguez Arancón is a Research Assistant at the Departamento de Filologías Extranjeras y sus Lingüísticas, Universidad Nacional de Educación a Distancia (UNED). Among her academic interests are English for Specific Purposes, the use of technology in foreign language education, bilingualism and cultural awareness. 
Elena Bárcena is a Senior Lecturer in English Language and Linguistics at the Departamento de Filologías Extranjeras y sus Linguiísticas (UNED). Her research interests focus on the teaching and analysis of sublanguages for computational purposes. She has researched on CALL-related topics and has published extensively in this field at both national and international levels.

Jorge Arús is an Associate Professor at the Departamento de Filología Inglesa of the Universidad Complutense de Madrid. His publications include articles on contrastive linguistics and second language teaching, within the systemic functional framework, in various national and international journals and edited volumes. He is currently copy-editor of Atlantis and b-learning coordinator at the School of Language of Linguistics, UCM. 